\title{
8
}
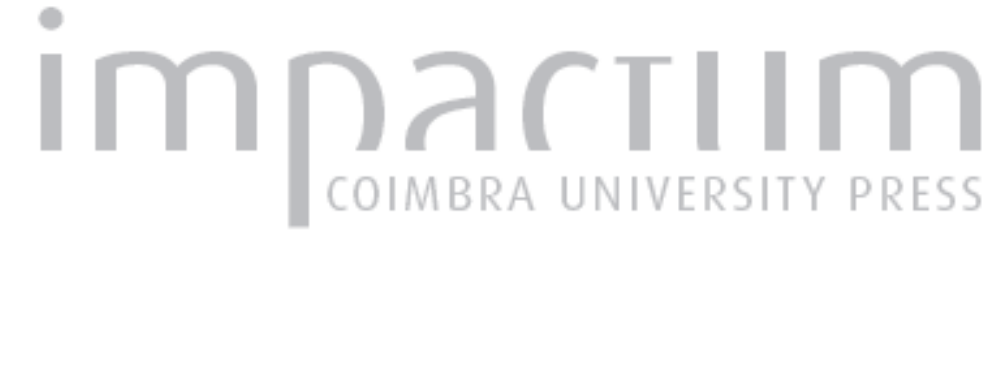

\section{Para uma terminologia portuguesa da métrica grega}

Autor(es): Lourenço, Frederico

Publicado por: Associação Portuguesa de Estudos Clássicos; Instituto de Estudos

URL persistente:

URI:http://hdl.handle.net/10316.2/30344

DOI:

DOI:http://dx.doi.org/10.14195/0872-2110_55_2

Accessed : $\quad$ 26-Apr-2023 16:29:34

A navegação consulta e descarregamento dos títulos inseridos nas Bibliotecas Digitais UC Digitalis, UC Pombalina e UC Impactum, pressupõem a aceitação plena e sem reservas dos Termos e Condições de Uso destas Bibliotecas Digitais, disponíveis em https://digitalis.uc.pt/pt-pt/termos.

Conforme exposto nos referidos Termos e Condições de Uso, o descarregamento de títulos de acesso restrito requer uma licença válida de autorização devendo o utilizador aceder ao(s) documento(s) a partir de um endereço de IP da instituição detentora da supramencionada licença.

Ao utilizador é apenas permitido o descarregamento para uso pessoal, pelo que o emprego do(s) título(s) descarregado(s) para outro fim, designadamente comercial, carece de autorização do respetivo autor ou editor da obra.

Na medida em que todas as obras da UC Digitalis se encontram protegidas pelo Código do Direito de Autor e Direitos Conexos e demais legislação aplicável, toda a cópia, parcial ou total, deste documento, nos casos em que é legalmente admitida, deverá conter ou fazer-se acompanhar por este aviso.

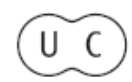




\section{Boletim de \\ Estudos Clássicos}

Associação Portuguesa de Estudos Clássicos

Instituto de Estudos Clássicos

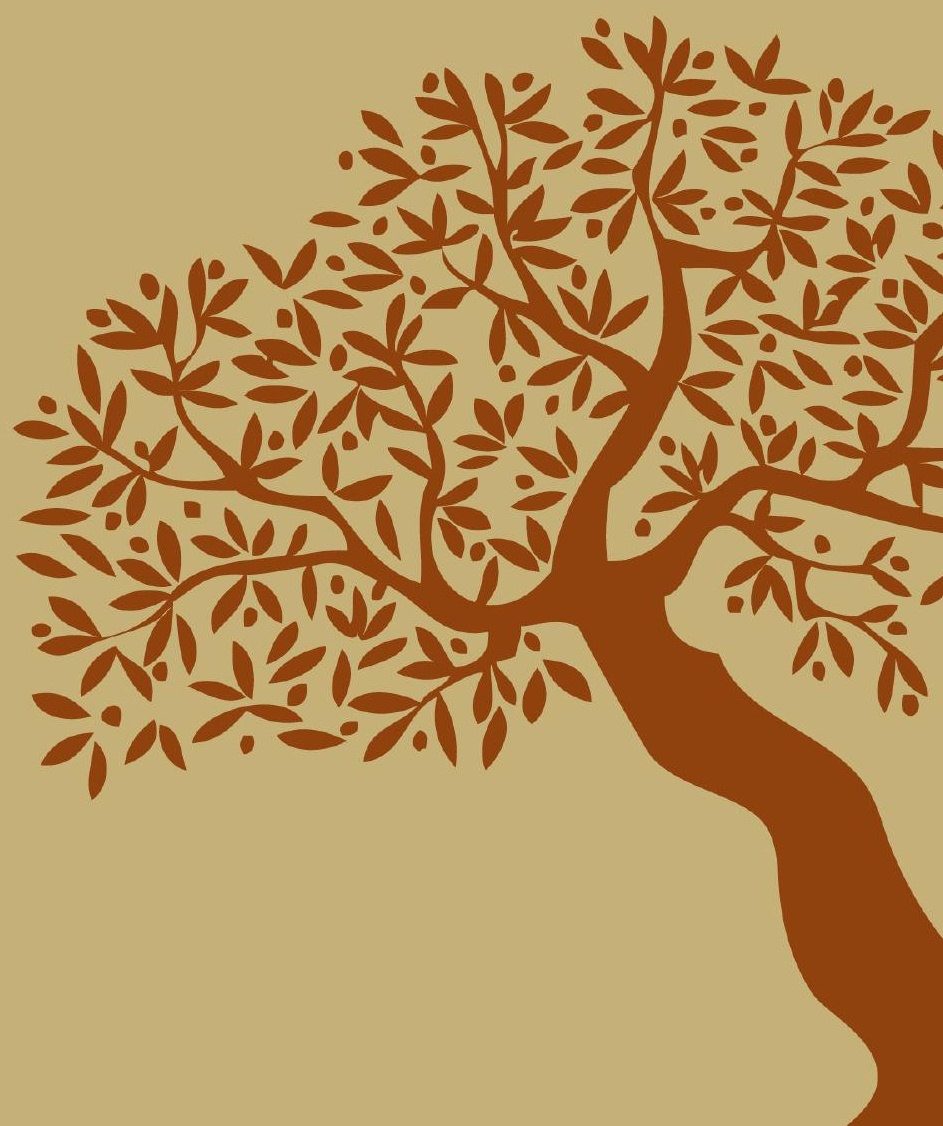

Coimbra

Junho de 2011 


\section{Para uma Terminologia Portuguesa DA MÉTRICA GREGA}

O estudo da métrica grega corresponde a uma área dos Estudos Clássicos que, depois do louvável contributo do Doutor Manuel de Oliveira Pulquério nos anos 60 do século passado, nunca chegou a ter grande expressão no espaço lusófono (ainda que helenistas de gerações mais novas, como Carlos Morais e Sofia Frade, a ela se tenham dedicado; ver Bibliografia no final deste artigo). Talvez por isso, nunca se normalizou (pelo menos em Portugal) a nomenclatura a utilizar na análise métrica da poesia grega. No entanto, há claras vantagens em dispormos de uma terminologia comummente aceite; e o presente artigo terá cumprido a sua função se, além de propor termos que possam ser geralmente utilizados, contribuir para uma maior curiosidade dos jovens leitores da poesia grega quanto à sua forma rítmica, que é um factor estético longe de ser secundário - dir-se-ia, pelo contrário, que é absolutamente determinante.

O material apresentado divide-se em duas secções:

(1) Símbolos métricos;

(2) Glossário de termos.

\section{Símbolos métricos ${ }^{1}$}

\begin{tabular}{|c|c|}
\hline$\cup$ & sílaba breve \\
\hline - & sílaba longa \\
\hline $\mathrm{x}$ & posição ancípite \\
\hline$\cup \cup$ & longa resolvida \\
\hline oo & base eólica \\
\hline & (syllaba) breuis in (elemento) longo \\
\hline A & indica sincopação \\
\hline & 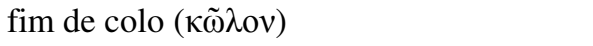 \\
\hline & fim de período métrico \\
\hline & fim de período métrico marcado por hiato \\
\hline
\end{tabular}

${ }^{1}$ Para uma definição dos termos utilizados (ancípite, sincopação, etc.), ver infra, Glossário. 


$\begin{array}{ll}\|^{\mathrm{B}} & \text { fim de período métrico marcado por breuis in longo } \\ \| & \text { fim de estância ou de composição lírica } \\ \otimes & \text { início de estância ou de composição lírica } \\ \int^{\otimes} & \begin{array}{l}\text { sinartese (enjambement) entre colos } \\ \text { em correspondência (in responsione) }\end{array}\end{array}$

\section{Glossário}

Adónico $(-\cup \cup-\longrightarrow)$ : pequeno colo, que surge normalmente em

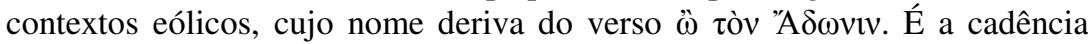
final da estrofe sáfica.

Anáclase: mudança ou redistribuição de posições longas e breves no interior de um colo ou metro. Assim, pode dizer-se que o wilamowitziano (oo $-\mathrm{x}-\cup \cup-$ ) é a forma anaclástica do glicónico (oo $-\cup \cup-\cup-$ ), ou o anacreôntico $(\cup \cup-\cup-\cup-\longrightarrow)$ a forma anaclástica do dímetro iónico $(\cup \cup-\longrightarrow \cup \cup-\longrightarrow)$.

Anacreôntico $(\cup \cup-\cup-\cup-\longrightarrow)$ : forma anaclástica do dímetro iónico $\left(\cup \cup-\_\cup \cup-\longrightarrow\right)$, utilizada por Anacreonte e na colectânea Poemas Anacreônticos.

Anapesto $(\cup \cup-\cup \cup-)$ : metro que surge normalmente sob a forma de dímetros, em que as duas breves podem ser contraídas numa longa e a longa resolvida em duas breves (o que explica o aparente aspecto "dactílico" de algumas sequências anapésticas). No teatro ático, era preferencialmente o metro recitativo. Cada sequência de anapestos recitados termina obrigatoriamente com a forma cataléctica do dímetro anapéstico, o paremíaco. Esta regra não se aplica aos anapestos mélicos (ou cantados), onde os paremíacos surgem com mais liberdade, inclusive a abrir uma sequência de anapestos cantados (como, por exemplo, na monódia de Creúsa no Íon de Eurípides: v. 859).

Ancípite: posição que pode ser ocupada por uma sílaba longa ou breve. É o caso, por exemplo da primeira posição do iambo $(\mathrm{x}-\cup-$ ), ou da última posição do troqueu $(-\cup-x)$. Barrett (1964) 422-423 considera ancípites as últimas posições dos colos eólicos pendentes $(\cup-\mathrm{x}$, em vez da interpretação mais geralmente aceite $\cup-\longrightarrow$ ), mas a questão é controversa.

Aristofânico ( $\cup \cup-\cup-\longrightarrow$ ): colo eólico que, a despeito do nome, não surge com especial frequência nas comédias conservadas de Aristófanes (cf. Parker (1997) 82-84), ainda que haja uma sequência curiosa 


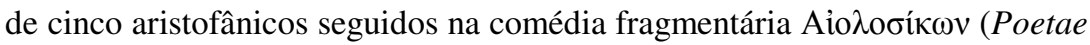
Comici Graeci 9).

Asclepiadeu: o termo, actualmente, não é muito utilizado na métrica grega, mas pode designar um glicónico (oo $-\cup \cup-\cup-$ ) com expansão coriâmbica, isto é, com acrescento de um ou mais coriambos (e.g. oo $-\cup \cup$ $-\longrightarrow \cup \cup-\cup-)$

Baquio ( $\cup-$-): forma sincopada do metro iâmbico $(=\cup-[\cup]-)$, cuja forma pendente é frequentemente utilizada para fechar um período métrico. É o segundo elemento do dímetro iâmbico sincopado conhecido como "itifálico" (crético + baquio).

Base eólica (oo): posições ancípites que antecedem o coriambo $(-\cup$ $\cup-$ ) nalguns colos eólicos como o glicónico, o ferecrácio, o hiponacteu, etc. Pode surgir sob a forma $-\longrightarrow,-\cup, \cup-\mathrm{e}$, no teatro ático, $\cup \cup \cup$. Não se anota a base eólica "x x", porque tal notação daria a entender que uma forma possível seria " $\cup \cup$ ".

Breuis in longo: quando a última posição longa de um verso é ocupada por uma sílaba breve (e começando o verso seguinte por vogal ou ditongo), refere-se essa sílaba como syllaba breuis in elemento longo, ou abreviadamente breuis in longo. Tal fenómeno, à semelhança do hiato, indica sempre o fim de um período métrico. Foi esta compreensão da incidência de breuis in longo e de hiato em Píndaro que permitiu a Boeckh em 1811 (Pindari Carmina Quae Supersunt, Leipzig) optar por uma colometria diferente da transmitida pelos manuscritos bizantinos e dispor os versos de Píndaro divididos em períodos e não em colos (como sucede ainda nas edições do teatro grego). A expressão breuis in longo foi inventada por Paul Maas (cf. West (1982a) 288).

Catalexe: supressão ou fusão final de uma posição final com efeito clausular. Pode dizer-se assim, por exemplo, que o ferecrácio (oo $-\cup \cup-$ $-)$ é a forma cataléctica do glicónico (oo $-\cup \cup-\cup-)$; o baquio ( $\cup-$ -), a forma cataléctica do iambo (x- $\cup-$ ); e o crético $(-\cup-)$, a forma cataléctica do troqueu $(-\cup-x)$. Se determinado género métrico é predominantemente de final hebetante $(\cup-)$, a sua forma cataléctica será pendente $(\cup-\longrightarrow)$; se predominantemente de final pendente $(\cup-\longrightarrow)$, a forma cataléctica será hebetante $(\cup-)$. Na prática, porém, é mais frequente e natural a forma cataléctica assumir forma pendente $(\cup--)$. Sobre este fenómeno leiam-se os importantes artigos de Parker (1976) e de West (1982a) 281-286. 
Cesura: habitual fim de palavra no interior de um metro.

Cirenaico $(\cup \cup-\cup \cup-\cup-\cup-$ ): colo enóplio, encontrado apenas na lírica de Eurípides.

Colo ( $\kappa \tilde{\omega} \lambda \circ \nu)$ : termo preferível a "verso" para designar medidas como "glicónico", "trímetro iâmbico", "hexâmetro dactílico", etc. Se as medidas a que nós chamamos colos seriam reconhecidas como tal pelos poetas gregos da época arcaica e clássica é questão sobre a qual paira ainda alguma dúvida entre os especialistas de métrica grega, dado que a colometria (divisão dos textos líricos em colos) foi inventada pelos alexandrinos e nada nos garante que as medidas produzidas pelas suas colometrias correspondessem à intenção original dos poetas. As divisões tradicionais que vemos nas edições consagradas dos poetas dramáticos são mais ou menos as que figuram nos manuscritos bizantinos, por sua vez herdadas das divisões alexandrinas (como provam muitos papiros helenísticos). O caso de Píndaro é diferente, já que o maior número de repetições do mesmo esquema rítmico nos seus poemas permite uma compreensão melhor da organização das estâncias em períodos métricos, o que autoriza e justifica uma disposição gráfica diferente da que prudentemente se tem seguido na edições de Ésquilo, Sófocles, Eurípides e Aristófanes. Mas a tendência actual é também, no caso destes poetas, no sentido do afastamento da colometria tradicional, como se vê pela recente edição da Electra de Sófocles de P. J. Finglass (Cambridge, 2007). Sobre toda esta problemática a leitura mais indicada é Parker (2001).

Colose $(\chi \omega \dot{\lambda} \omega \sigma \iota \varsigma)$ : este termo tem por referente o aparecimento de uma sílaba longa numa posição onde se esperaria uma breve. Os estudos da grande especialista A(my). M. Dale consagraram em inglês a expressão drag para designar colose, mas nem todos os helenistas anglo-saxónicos concordam.

Contracção: fusão de duas breves numa longa.

Coriambo $(-\cup \cup-)$ : o metro característico da lírica eólica. Pode também surgir em contextos iâmbicos e trocaicos, como forma anaclástica desses metros.

Correspondência (ing. responsion): no par de estâncias "gémeas" a que chamamos estrofe e antístrofe, a antístrofe reproduz exactamente o esquema métrico da estrofe, pelo que cada verso de uma "corresponde" ao verso da outra em igual posição. O sinal normalmente utilizado para indicar correspondência entre versos é “ ”, pelo que a referência, por exemplo, a Antígona 783 793 significa que o v. $783(\cup-\cup \cup-\cup--)$ corresponde na antístrofe com o v. 793 ( $\cup-\cup \cup-\cup-\longrightarrow)$, tendo ambos a mesma forma métrica, o hagesícoro. Esta regra da composição estrófica é 
determinante na consideração de problemas de crítica textual, pois se os manuscritos transmitem formas que põem em causa a correspondência exacta entre os versos, isso significa que não estão a transmitir a versão original do poeta, mas sim corruptelas (muitas delas já corrigidas por meio de conjecturas e emendas desde o século XVI, ainda que algumas ainda coloquem desafios aos helenistas). Uma vez que os Bizantinos tinham noções apenas aproximativas do que eram as regras da métrica grega arcaica e clássica, incorriam naturalmente em erros involuntários na cópia dos manuscritos.

Crético $(-\cup-)$ : em contextos iâmbicos e trocaicos, o crético pode ser entendido como forma sincopada desses metros, mas além disso encontramos sequências de créticos que sugerem que se trataria também de

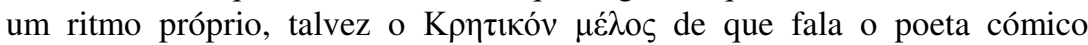
Cratino (Poetae Comici Graeci 237), que surge com especial destaque nos coros dos Acarnenses de Aristófanes.

Dáctilo $(-\cup \cup)$ : o metro característico da epopeia, mas que aparece também em contextos líricos, quer sob a forma de hexâmetro, quer sob a forma de tetrâmetro.

Dáctilo-epítrito: designação genérica que se dá ao ritmo lírico constituído pela frase $-\cup \cup-\cup \cup-$ ("D") e seus prolongamentos (-

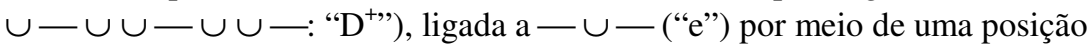
ancípite. Sensivelmente metade das odes conservadas de Píndaro estão compostas neste ritmo, que surge também nas partes corais da tragédia (no caso de Ésquilo, apenas no Prometeu Agrilhoado, cuja autoria esquiliana é duvidosa) e nos Cavaleiros de Aristófanes.

Decassílabo alcaico ( $\cup \cup-\cup \cup-\cup--)$ ): verso final da estrofe alcaica, também utilizado por Ésquilo, Sófocles e Eurípides.

Diérese: fim de palavra no final de um metro, como por exemplo a diérese bucólica do hexâmetro dactílico, que ocorre no final do quarto metro.

Dístico elegíaco: conjunto de dois versos, hexâmetro dactílico e "pentâmetro" (na realidade, a repetição do primeiro hemistíquio do hexâmetro: $-\cup \cup-\cup \cup-1-\cup \cup-\cup \cup-$, designando aqui "l" fim de palavra).

Diomedeu $(-\cup \cup-\cup \cup-\cup-x)$ : colo enóplio, sobre o qual leiase Itsumi (1991-1993).

Dócmio $(\mathrm{x}-\mathrm{x}$ - $)$ : metro característico da lírica trágica, utilizado em contextos de agitação emotiva. A sua forma é proteica, uma vez que cada 
uma das longas pode ser resolvida, o que dá 32 variações matematicamente possíveis. Na verdade, nem todas estão atestadas nas peças que nos chegaram do teatro ático. Sobre este metro, ver Conomis (1964).

Dócmio kaibeliano $(\mathrm{k} \delta: \mathrm{x}-\mathrm{x}-\cup-)$ : variação pouco frequente do dócmio.

Dodrante (dod: $-\cup \cup-\cup-$ ): a frase basilar da lírica eólica.

Enóplio: trata-se de um dos termos métricos mais antigos, já que Aristófanes o menciona nas Nuvens (v. 651), embora não seja fácil perceber a que realidade o poeta cómico se está a referir. Os modernos especialistas de métrica grega dividem-se no que toca à definição (e mesmo utilidade) do termo, mas uma definição operativa poderia ser esta: enóplio aplica-se ao grupo de frases rítmicas que diferem (1) da lírica dactílica porque admitem uma ou duas breves iniciais e a sequência “... - x (-)..." onde numa sequência dactílica teríamos “...- $\cup \cup(-) .$. ”; e diferem (2) da lírica dáctilo-epítrita porque as unidades constitutivas se juntam umas às outras sem ancípites de permeio. Por outras palavras, um colo é enóplio se, mau grado a presença de elementos dactílicos e/ou anapésticos, não pode ser analisado como uma sequência dactílica (tetrâmetro dactílico, hexâmetro dactílico), nem como sequência de unidades dáctilo-epítritas unidas por "x".

Eólico: o adjectivo "eólico" descreve genericamente todo o leque de colos (que em muitos casos já vem da poesia de Alceu e Safo) que contêm um núcleo coriâmbico $(-\cup \cup-)$, normalmente seguido de " $\cup-$ ", como no dodrante $(-\cup \cup-\cup-$ ). O colo eólico mais utilizado é o glicónico (oo $\cup \cup-\cup-)$.

Erasmonidiano (erasm: $x-\cup \cup-\cup \cup-x$ ): colo que surge em contextos enóplios.

Espondeu (sp: - - ): o espondeu pode representar um dáctilo com contracção das duas breves, ou um metro iâmbico ou trocaico com sincopação dupla.

Estrofe alcaica: estrofe cuja forma impressa nas edições modernas tem a forma de uma quadra. Os primeiros dois versos são idênticos (pentemímere + dodrante: $\mathrm{x}-\cup-\mathrm{x}-\cup \cup-\cup-$ ); o terceiro verso $(\mathrm{x}-\cup-\mathrm{x}-\cup$ - $\mathrm{x}$ ) é de análise mais complexa (talvez iambo + pentemímere). $\mathrm{O}$ último verso é o decassílabo alcaico (- $\cup \cup-\cup \cup-\cup-\longrightarrow)$.

Estrofe sáfica: estrofe cuja forma impressa nas edições modernas tem a forma de uma quadra, constituída por três hendecassílabos sáficos (crético + hagesícoro: $-\cup-\mathrm{x}-\cup \cup-\cup-\longrightarrow$ ) e um adónico (- $\cup \cup-\longrightarrow$ ). 
Ferecrácio (ph: oo $-\cup \cup-\longrightarrow$ ): forma cataléctica do glicónico (oo $-\cup \cup-\cup-)$.

Glicónico (gl: oo $-\cup \cup-\cup-$ ): o colo eólico mais frequente na lírica grega.

Hagesícoro (hag: $x-\cup \cup-\cup-\longrightarrow$ ): forma "acéfala" do hiponacteu (oo - $\cup \cup-\cup-\longrightarrow$ ). Termo inventado por West (1982) $30 \mathrm{n}$.

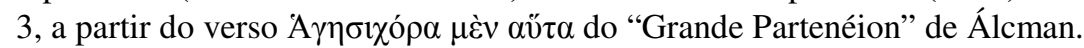

Hebetante (inglês blunt, alemão stumpf): o final " $\cup$ - " de um colo, por oposição a pendente $(\cup-\longrightarrow)$. Ver também a definição de Catalexe.

Heftemímere: a cesura (menos frequente do que a pentemímere) que, no hexâmetro dactílico e no trímetro iâmbico, surge após a primeira posição do quarto metro.

Hemistíquio: uma das metades de um verso dividido por cesura. eólico.

Hendecassílabo falécio (phal: oo $-\cup \cup-\cup-\cup-\longrightarrow$ ): colo

Heptassílabo eólico (hept: $\mathrm{x}-\mathrm{x}-\cup \cup-$ ): colo eólico.

Hexâmetro dactílico ( 6 da: $-\cup \cup-\cup \cup-\cup \cup-\cup \cup-\cup \cup$ - -): o verso próprio da epopeia. As breves podem ser contraídas, ainda que esse fenómeno seja raro no quinto metro. A cesura é normalmente pentemímere (a seguir à primeira posição do terceiro metro), mas pode também ser heftemímere (a seguir à primera posição do quarto metro). Chama-se "diérese bucólica" ao fim de palavra que ocorre por vezes no final do quarto metro.

Hexassílabo eólico (hex: oo $-\cup \cup-$ ): colo eólico.

Hiato: um dos critérios mais seguros (juntamente com breuis in longo) para a definição do fim de um período métrico é a presença de hiato entre o final de um colo e o início do outro. Se um colo acaba em vogal ou ditongo e o colo seguinte começa com vogal ou ditongo, o hiato daí resultante marca a existência de uma pausa métrica e consequente fim de período.

Hipodócmio (h $\delta:-\cup-\cup-$ ): variação pouco frequente do dócmio.

Hiponacteu (hipp: oo $-\cup \cup-\cup-\longrightarrow$ ): colo eólico.

Iambo (ia: $x-\cup-$ ): o trímetro iâmbico é, por excelência, o verso das partes faladas do teatro ático, onde está sujeito à obrigatoriedade de uma cesura (normalmente pentemímere) e a outros espartilhos, como a chamada Lei de Porson. Sobre o trímetro iâmbico em geral, e em especial sobre o sofocliano, veja-se o magnífico estudo de Morais (2010). Nas partes líricas da tragédia, os iambos surgem com maior possibilidade de resolução do que nas 
partes faladas, ainda que haja restrições no que toca à resolução de uma posição longa repartida entre o fim de uma palavra e o início de outra (split resolution em inglês), tema sobre o qual o estudo fundamental é Parker (1968), e restrições ainda quando à admissibilidade do fim de palavra depois de uma ancípite longa: cf. Parker (1966).

Ibiceu (ibyc: $-\cup \cup-\cup \cup-\cup-$ ): colo repetido três vezes no

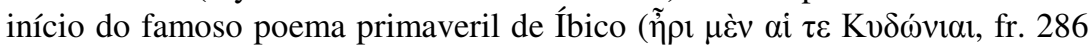
Page) e utilizado em contextos quer eólicos, quer enóplios, por Ésquilo, Sófocles, Eurípides e Aristófanes. Itsumi (1984) 71-72 argumentou com razão que, em rigor, a penúltima posição do ibiceu deve ser considerada ancípite.

Iónico (io: $\cup \cup-\longrightarrow$ ): metro por vezes considerado de conotações exóticas, característico (por exemplo) dos coros das Bacantes de Eurípides.

Itifálico (ith: $-\cup-\cup--$ ): dímetro iâmbico sincopado, frequentemente utilizado com cláusula para marcar o fim de um período métrico ou fim de uma estância.

Lecítio (lk: $-\cup-\mathrm{x}-\cup-$ ): colo de uso frequente na lírica dramática (e não só), de classificação ambígua, dado que pode ser interpretado como "troqueu + crético" ou "crético + iambo". O nome deriva das palavras $\lambda \eta \kappa v ́ \theta ı v ~ d ̇ \pi \omega ́ \lambda \varepsilon \sigma \varepsilon \varepsilon$ repetidas várias vezes nas $R \tilde{a} s$ de Aristófanes (cf. v. 1208 e seguintes).

Lei de Porson: quando a ancípite do terceiro metro de um trímetro iâmbico é longa, essa sílaba e a seguinte pertencem à mesma palavra, a não ser que uma delas seja um monossílabo. Para a aplicação desta lei à lírica iâmbica, ver Parker (1966).

Molosso (mol: - - - ) : metro de classificação controversa, talvez uma derivação do metro iâmbico ou trocaico.

Palimbaquio (pa: $-\longrightarrow \cup$ ): forma sincopada do metro trocaico. Não ocorre com frequência, a não ser na Helena de Eurípides.

Paremíaco (prm: $\cup \cup-\cup \cup-\cup \cup-\longrightarrow$ ): forma cataléctica do dímetro anapéstico. Nos anapestos recitados, constitui a cláusula da sequência. Nos anapestos mélicos, pode surgir em qualquer posição da sequência. Dado que as longas podem ser resolvidas e as breves contraídas, várias são as formas possíveis deste colo, até uma forma que consiste em sete longas seguidas.

Período métrico: na lírica grega, as unidades métricas (metros, colos) são organizadas em períodos de maior ou menor extensão, no final dos quais se pressupõe uma pequena pausa. O fim do período métrico coincide também, 
na maior parte dos casos, com uma pausa sintáctico-semântica. Os critérios para determinar o fim do período são (1) fim de palavra, sem elisão; (2) presença de hiato, de breuis in longo ou de duas ancípites contíguas; (3) catalexe, pausa semântica, modulação rítmica (mudança de um tipo de metro para outro). O facto de, nas odes de Píndaro, os esquemas métricos serem repetidos várias vezes permite dispor graficamente as estâncias de modo a que cada verso equivalha a um período; no caso da lírica dramática, tal opção é menos viável, em virtude de cada esquema métrico ser repetido apenas duas vezes e, em muitos casos, nos faltarem os dois critérios incontroversos para a determinação de fim de período (hiato e breuis in longo).

Pendente (inglês pendant, alemão klingend): o final " $\cup-\ldots$ " de um colo, por oposição a hebetante $(\cup-)$. Ver também a definição de Catalexe.

Pentemímere (cesura): a cesura que, no hexâmetro dactílico $(-\cup \cup$ $-\cup \cup-\mid \cup \cup-\cup \cup-\cup \cup-\longrightarrow$ ) e no trímetro iâmbico ( $\mathrm{x}-\cup-\mathrm{x} \mid$ $-\cup-x-\cup-)$, surge após a quinta posição.

Pentemímere (pe: $\mathrm{x}-\cup-\mathrm{x}$ ): pequeno colo que aparece em contextos eólicos e iâmbicos.

Praxileu (prax: $-\cup \cup-\cup \cup-\cup \cup-\cup-\longrightarrow$ ) colo que, em Ésquilo, Sófocles e Eurípides, surge em contexto eólico ou enóplio.

Reiziano (reiz: $x-\cup \cup-\longrightarrow$ ): colo eólico.

Resolução: entende-se por resolução o desdobramento de uma longa em duas breves.

Sinartese: conceito de definição controversa, mas que pode utilizar-se com proveito para designar o prolongamento (enjambement) da palavra final de um colo no colo seguinte. O sinal utilizado para indicar este fenómeno é

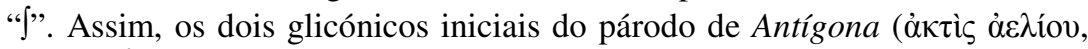

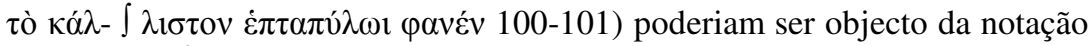
sintética "gl $\int \mathrm{gl}$ ".

Sincopação: posição ou posições suprimidas, por vezes indicada por meio de " $\wedge$ ”. Assim, um baquio $(\cup-\longrightarrow)$, que é uma forma sincopada do iambo $(\mathrm{x}-\cup-)$, pode também ser notado "ia^".

Telesileu (tel: $x-\cup \cup-\cup-$ ): a forma "acéfala" do glicónico (oo $-\cup \cup-\cup-$ ). O colo $\cup \cup-\cup \cup-\cup-$ parece ter uma identidade diferente do telesileu (cf. West (1982) 120) e por isso Willink, na sua edição do Orestes de Eurípides (Oxford, 1986, p. xxi), atribui-lhe a designação "T". Além de aparecer em contextos eólicos, "T" surge também em contextos enóplios. 
Tríade: conjunto de três estâncias formado por estrofe, antístrofe e epodo, sendo que estrofe e antístrofe são estâncias "gémeas", repetindo a antístrofe exactamente a mesma métrica da estrofe, ao passo que o epodo tem um esquema métrico próprio. Nas odes de Píndaro de estrutura triádica, todas as estrofes e antístrofes correspondem entre si, sucedendo o mesmo com os epodos. $\mathrm{Na}$ odes da tragédia e da comédia, cada novo par estrófico introduz um esquema métrico diferente do par estrófico anterior. Na lírica dramática, é mais frequente a utilização do par estrofe antístrofe (sem epodo), do que a estrutura tríadica estrofe antístrofe + epodo.

Troqueu (tr: $-\cup-x$ ): o tetrâmetro trocaico era originalmente $o$ verso das partes faladas da tragédia, tendo sido depois substituído pelo trímetro iâmbico; a tragédia de Ésquilo já pertence a esta nova fase (embora Persas e Agamémnon contenham tetrâmetros trocaicos). No entanto, nas peças da fase final da carreira de Eurípides a partir de Troianas (415 a.C.), depara-se-nos uma recuperação curiosa, quase arcaizante, dos tetrâmetros trocaicos, introduzindo um aumento da temperatura emocional do drama, como no caso famoso da entrada de Pílades em Orestes. Também na fase final da produção euripidiana (Helena, Fenícias, Ifigénia em Áulide), encontramos interessantes sequências líricas em ritmo trocaico. Na comédia aristofânica, os tetrâmetros trocaicos são ocorrência frequente.

Wilamowitziano (wil: oo $-\mathrm{x}-\cup \cup-$ ): como o nome indica, colo identificado e estudado por Wilamowitz (no seu livro Griechische Verskunst), embora seja também conhecido como "dímetro coriâmbico" (erroneamente, já que nunca é constituído por dois coriambos), como "poli-esquemático" e, mais acertadamente, como "glicónico anaclástico", uma vez que um glicónico na estrofe, por exemplo, pode corresponder com um wilamowitziano na antístrofe. Sobre este colo o estudo fundamental é o de Itsumi (1982).

\section{BIBLIOGRAFIA:}

BARRETT, W. S. (1964), Euripides, Hippolytos, Oxford.

CONOMIS, N. C. (1964), "The dochmiacs of Greek Drama", Hermes 92, 23 50.

DALE, A. M. (1968²), The Lyric Metres of Greek Drama, Cambridge. - (1969), Collected Papers, Cambridge.

FRADE, S. (2006), A Poética do Ciclo Coral de Fenícias: uma visita à oficina lírica de Eurípides, Lisboa (diss. Mestrado).

ITSUMI, K. (1982), “The 'Choriambic Dimeter' of Euripides”, Classical Quarterly 32, 59-74. 
- (1984), "The Glyconic in Tragedy", Classical Quarterly 34, 66-82.

- (1991-1993), "Enoplian in Tragedy", Bulletin of the Institute of Classical Studies 38, 243-261.

- (2009), Pindaric Metre: the 'Other Half', Oxford.

LOURENÇO, F. (2011), Euripidean Lyric Metre: A Survey, Coimbra (no prelo).

MORAIS, C. (1991), Expectativa e Movimento no Filoctetes, Coimbra.

- (1995), "Uma Catábase Agonístico-burlesca com contraposição rítmica (Ar. Ra. 208-268)", Humanitas 47, 307-325.

- (2010), O Trímetro Sofocliano: Variações sobre um Esquema, Lisboa.

PARKER, L. P. E. (1966), "Porson's Law Extended", Classical Quarterly $16,1-26$.

- (1968), "Split Resolution in Greek Dramatic Lyric", Classical Quarterly 18, 241-269.

- (1976), "Catalexis", Classical Quarterly 26, 14-28.

- (1997), The Songs of Aristophanes, Oxford.

- (2001), "Consilium et Ratio? Papyrus a of Bacchylides and Alexandrian Metrical Scholarship", Classical Quarterly 51, 23-52.

PULQUÉRIO, M. O. (1964), Estrutura e Função do Diálogo LíricoEpirremático em Ésquilo, Coimbra.

- (1969), Características Métricas das Monódias de Eurípides, Coimbra.

STINTON, T. C. W. (1990), Collected Papers on Greek Tragedy, Oxford.

WEST, M. L. (1982), Greek Metre, Oxford.

- (1982a), "Three Topics in Greek Metre", Classical Quarterly 32, 281-297.

WILAMOWITZ- MOELLENDORFF, U. von (1921), Griechische Verskunst, Berlin.

WILLINK, C. W. (2010), Collected Papers on Greek Tragedy, Leiden. 